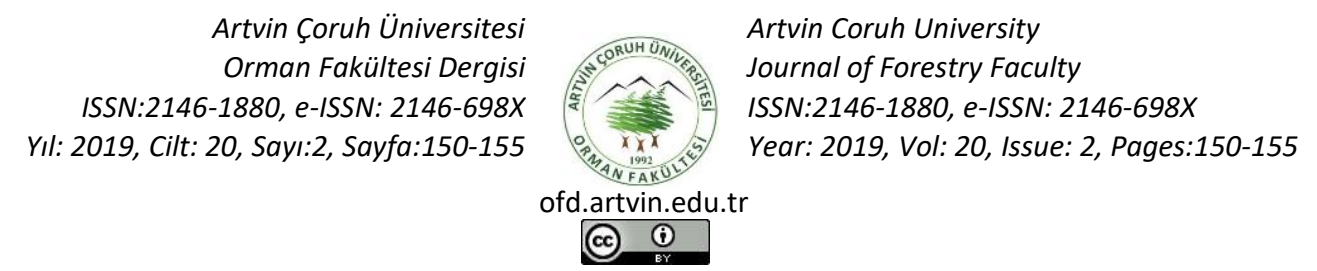

\title{
Güney Marmara ve Ege Bölgesindeki geyik elması (Malus trilobata C.K. Schneid.) gen kaynakları
}

\author{
The genetic resources of deer apple (Malus trilobata C.K. Schneid.) in Southern Marmara and Aegean Regions
}

\author{
Mustafa YILMAZ ${ }^{i}$, Salih PARLAK ${ }^{\text {iD }}$, Mehmet KALKAN \\ Bursa Teknik Üniversitesi Orman Fakültesi Orman Mühendisliği Bölümü, Bursa Türkiye
}

Eser Bilgisi/Article Info

Araştırma makalesi/Research article

DOI: $10.17474 /$ artvinofd.491712

Sorumlu yazar/Corresponding author

Mehmet KALKAN

e-mail: mehmet.kalkan@btu.edu.tr

Geliş tarihi / Received

03.12.2018

Düzeltme tarihi / Received in revised form

17.06.2019

Kabul Tarihi / Accepted

17.06.2019

Elektronik erişim / Online available

27.06.2019

Anahtar kelimeler:

Geyik elması

Malus trilobata

Doğal yayılış

Gen kaynakları

Keywords:

Deer apple

Malus trilobata

Natural distribution

Genetic resource

\begin{abstract}
Özet
Geyik elması (Malus trilobata C.K. Schneid.) ülkemizde nadir bulunan, kışın yaprağını döken ve dikensiz elma türlerinden biridir. Genel olarak ormanlarda ve tarımsal alanlarda, münferit veya küçük gruplar şeklinde yayılış gösterir. Doğal yayılışının büyük çoğunluğu Türkiye'de özellikle Akdeniz Bölgesi'nde bulunmaktadır. Genellikle 250-1500 m yükselti aralığında bulunur. Bu çalışmada, çok sınırlı kayıtların olduğu Ege ve Güney Marmara bölgelerindeki geyik elmasının doğal yayılış alanları tespiti amaçlanmıştır. Türün bölgedeki dağılışını belirlemek amacıyla il ve ilçelerde bulunduğu mevkiler, koordinatları, rakımı ve bakısı belirlenmiştir. Belirlenen her bir ağacın gövde çapı ve boyu ölçülmüştür. Ayrıca genotiplerin bulunduğu yerin mülkiyeti ve bitki örtüsü kaydedilmiştir. Çalışma sonucunda Denizli, Muğla, İzmir, Manisa ve Balıkesir'de çok sayıda geyik elması tespit edilmiştir. Balıkesir ve Denizli'de daha fazla genotip gözlemlenmiştir. Çalışılan alanlarda genel olarak geyik elmasına $250 \mathrm{~m}$ ile $1300 \mathrm{~m}$ rakımlar arasında rastlanmıştır. Daha ayrıntılı arazi taraması ile türün Güney Marmara ve Ege Bölgesi'nde çok daha fazla mevkide bulunabileceği anlaşıımaktadır. Yayılışının tamamına yakını ülkemizde bulunan bu türün doğal yayılışının ve yetişme ortamlarının tam olarak tespit edilmesine ihtiyaç bulunmaktadır. Türün söz konusu bölgelerdeki gen kaynakları kaydedilmeli ve koruma altına alınmalıdır. Meyveye yönelik bahçe kurulması ve süs bitkisi üretimi amaçlı kültüre alınma olanakları ayrıntılı olarak çalışılmalıdır.
\end{abstract}

\begin{abstract}
Deer apple (Malus trilobata C.K. Schneid.) is one of the rare wild fruit and broadleaved trees in Turkey. It is scattered in forests and agricultural areas, generally in individual or small groups. The majority of the natural distribution is situated in Turkey, especially in the Mediterranean region. The deer apple generally occurs at 250- $1500 \mathrm{~m}$ altitude. In this study, it is aimed to determine the natural distribution areas and individuals of the deer apple in the Aegean and Southern Marmara regions with very limited records. In order to determine the distribution of the species in the regions, the coordinates, altitudes, aspects and positions of the provinces and districts have been recorded. The diameter and height of each individual was measured and also were recorded the property and vegetation of the place where the individuals were found. As a result of the study, deer apple individuals were found in Denizli, Muğla, İzmir, Manisa, and Balikesir in many places, especially much more in Balıkesir and Denizli. The individuals determined in the study areas are between $250 \mathrm{~m}$ and $1300 \mathrm{~m}$. It is understood that there are many more places in Southern Marmara and Aegean region with more detailed land research. The natural distribution and habitat of the deer apple exactly should be determined in Turkey. The genetic resources of $M$. trilobata should be recorded and carefully protected.
\end{abstract}

\section{GiRiş}

Türkiye, yabani meyve ağaç türleri bakımından oldukça zengin bir konuma sahiptir. Yabani meyveler, kısıtlı alanlarda ve az sayıda olmasından dolayı kıymetlidirler. Çoğu belirli amaçlarla kullanılmasına rağmen, önemi ve değeri günümüzde yeterince bilinmemektedir. Yabani meyveler, barınma ve besin kaynağı açısından birçok hayvana yaşam alanı oluşturmaktadır. İğne yapraklı ve geniş yapraklı türlerle karışıma girerek hem biyoçeşitliliğin artmasında hem de karışık ormanların oluşturulmasına katkıda bulunurlar. Ayrıca yabani türlerin meyveleri yöre halkı tarafından kendi ihtiyaçlarını karşılamanın yanı sıra ticari açıdan da çeşitli ürünlere dönüştürülerek kullanılmaktadır. Etnobotanikte de bu yabani meyvelerden yaygın olarak yararlanılmaktadır.

Insan kaynaklı tahribatların artması sonucu yabani meyve ağaçlarının sayısı giderek düşmektedir. Bunun önde gelen nedenleri, hatalı ormancılık uygulamaları ve değerinin bilinmemesinden dolayı yerel halk tarafından yakacak odun olarak bu türlerin tahrip edilmesidir. Bu türlerin biyolojik ve genetik çeşitlilik açısından koruma altına alınması, her bir türün kaydedilmesi ve doğal olarak 
bulunan popülasyonların restore edilmesi büyük önem taşımaktadır (Küçük ve ark. 2008).

Geyik elması (Malus trilobata C.K. Schneid.) Türkiye'de ender bulunan dikensiz yabani fakat dikensiz türlerden birisidir. Ülkemizde genel olarak münferit veya gruplar halinde yayılış gösteren ve son yıllarda üzerine çalışmalarda bulunulmuş orman ağaçlarından biridir (Browicz and Karaca 1993; Işık ve Dönmez 2004; Türkmen ve ark. 2004; Qian et al. 2006; Gültekin ve ark. 2007; Yılmaz 2008; Yılmaz ve Ok 2012; Yılmaz ve Yüksel 2016).

Doğal olarak dünyada sadece Akdeniz havzasında yetişen M. trilobata; Bulgaristan, Yunanistan, Türkiye, Filistin, İsrail ve Lübnan'da bulunmaktadır (Browicz and Karaca 1993; Korakis et al. 2006; Gültekin 2011). Türkiye'de iç Anadolu, Ege ve Akdeniz bölgelerinde doğal yayılışını gerçekleştirmektedir (Browicz and Karaca 1993; Yaltırık 1996). M. trilobata Batı Akdeniz ve Ege Bölgelerinde "Geyik Elması" adıyla tanınırken; Doğu Akdeniz Bölgesinde "Geyik Elması", "At Elması" ve "Geyicek" adlarıyla bilinmektedir (Yılmaz ve Yüksel 2016). Meyveleri yerel halk tarafından birçok kullanım açısından istifade edilmektedir. Geyik elmasının bulunduğu her yörede odununun yakacak olarak kullanılması türü tahribata uğratmıştır. Özellikle içinde bulunduğumuz son yüzyılda geyik elması bireylerinin sayısı çok azalmıştır. Bu nedenle geyik elması gibi yabani meyve türlerinin çoğaltılması ve restore edilmesi önemlidir.

Bu çalışmada, geyik elmasının doğal yayılış alanları ve çok kısıtlı kayıtların olduğu Ege ve Güney Marmara bölgelerindeki bireylerinin tespiti amaçlanmıştır. Türe özgü etnobotanik bilgiler de derlenmiştir.

\section{MATERYAL VE YÖNTEM}

Geyik elması (Malus trilobata C.K. Schneid.), Rosaceae (Gülgiller) familyasında yer alan ve genellikle 5-10 m boylarında küçük bir ağaçtır. Uygun şartlarda 12 hatta 18 m'ye kadar boylanabilmektedir. Genellikle 250-1500 m yükselti aralığında bulunur. $M$. trilobata ilk kez Poiret tarafından 1810 yılında Crataegus trilobata olarak tanımlansa da, günümüzde Malus trilobata adıyla kabul edilmektedir. Muhtemelen türün ilk tespitini 1837 yılında Manisa'da Aucher-Eloy yapmıştır (Browicz and Karaca
1993). Tür üzerinde yapılan çalışmalarda göstermektedir ki, Türkiye'de Balıkesir, Manisa, İzmir, Muğla, Kütahya, Uşak, Isparta, Antalya, Konya, İçel, Kahramanmaraş, Gaziantep ve Hatay yörelerinde yayılış gösterdiği belirlenmiştir (Şekil 1). Trakya, Marmara, Güney Batı Anadolu ve Ege'de geyik elması yayılışının muhtemel olduğu ayrıca belirtilmektedir (Browicz 1982; Browicz ve Karaca 1993).

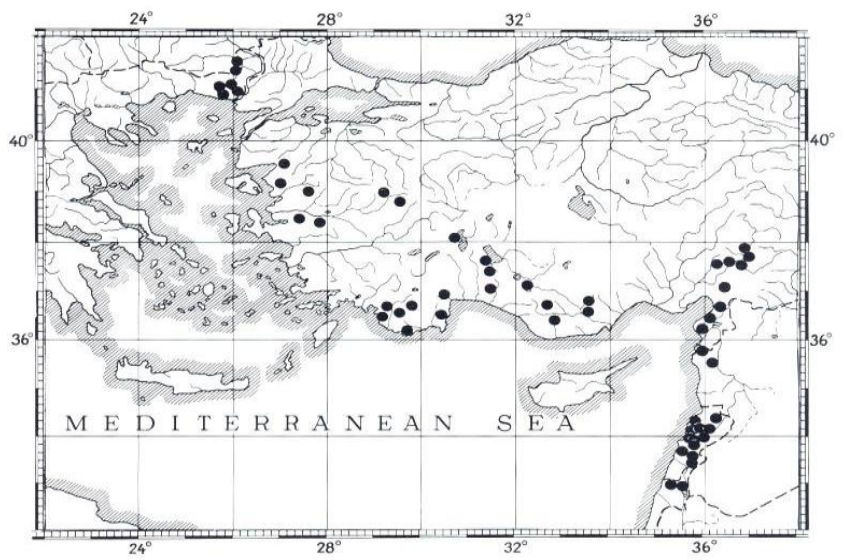

Şekil 1. Malus trilobata C.K. Schneid.'nın dünyadaki yayılışı (Boratyński et al. 1992).

Bu çalışmada, Geyik elmasının doğal yayılış alanları ve bireylerini belirlemek amacıyla Ege ve Marmara bölgelerinde çalışımıştır. Marmara bölgesinde Balıkesir ilinde; Ege bölgesinde ise İzmir, Manisa, Denizli ve Muğla illerinde türe ait bireyler tespit edilmiştir (Şekil 2). Türün bölgedeki dağılışını belirlemek amacıyla her il ve ilçelerde bulunduğu mevkiler, koordinatları, rakımı ve bakısı kayıt altına alınmıştır. Tespit edilen her bireyin çapı ve boyu ölçülmüştür (Yılmaz ve Yüksel 2006). Ayrıca bireylerin bulunduğu yerin mülkiyeti ve bitki örtüsü kaydedilmiştir.

\section{BULGULAR}

Yapılan arazi taraması sonucunda Balıkesir, Denizli, Muğla, İzmir ve Manisa'da çok sayıda grup ve münferit hallerde geyik elması bireyleri tespit edilmiştir. Tespit edilen bireylerin çoğunluğunda kayıt ve ölçümler yapılmıştır (Şekil 2). Bazı noktalarda ise varlıkları tespit edilmiş, ancak bireyler üzerinde ölçümler yapılamamıştır. 


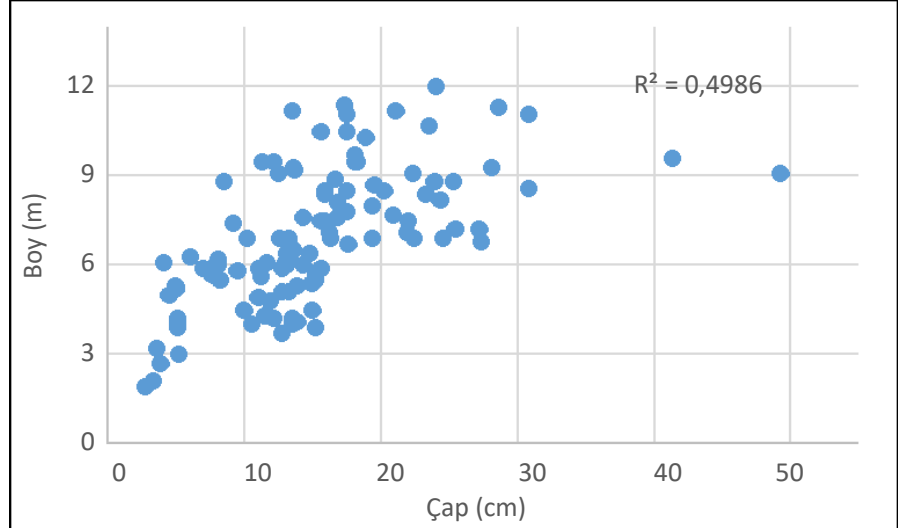

Şekil 2. Ege ve Güney Marmara'da ölçümü yapılan geyik elması bireylerine ait çap-boy grafiği.

Marmara bölgesinde en fazla birey Balıkesir'de belirlenmiştir. İvrindi ilçesi Geçmiş, Ayaklı, İkizce ve Taşdibi köylerinde Asar, Sarıtaş ve Bergama yolu mevkilerinde ormanlarda serpili olarak çok sayıda geyik elması belirlenmiştir. Ayrıca Balya ve Gönen ilçelerinde Danişment, Koyuneri, Örencik, Kocapınar, Orhanlar köyleri başta olmak üzere çok sayıda köyde tür bilinmektedir (Şekil 3). Toplamda Balıkesir ilinde 51 adet bireyde ölçüm yapılmıştır. Tespit edilen bireyler üzerinde yapılan gövde çapı ve ağaç boyu ölçümleri sonucu ortalama çap $18.7 \mathrm{~cm}$ ve ortalama boy $6.7 \mathrm{~m}$ olarak bulunmuştur. Balıkesir'de tespit edilen bireylerin yayılış yaptığı alanlar genel olarak kızılçam ormanlarıdır. Ortalama $465.5 \mathrm{~m}$ yükseltide ve çoğunlukla güney bakıda olduğu belirlenmiştir. Balıkesir yöresinde gicik elma, gıccık elma ve gece elması olarak da bilinmektedir.

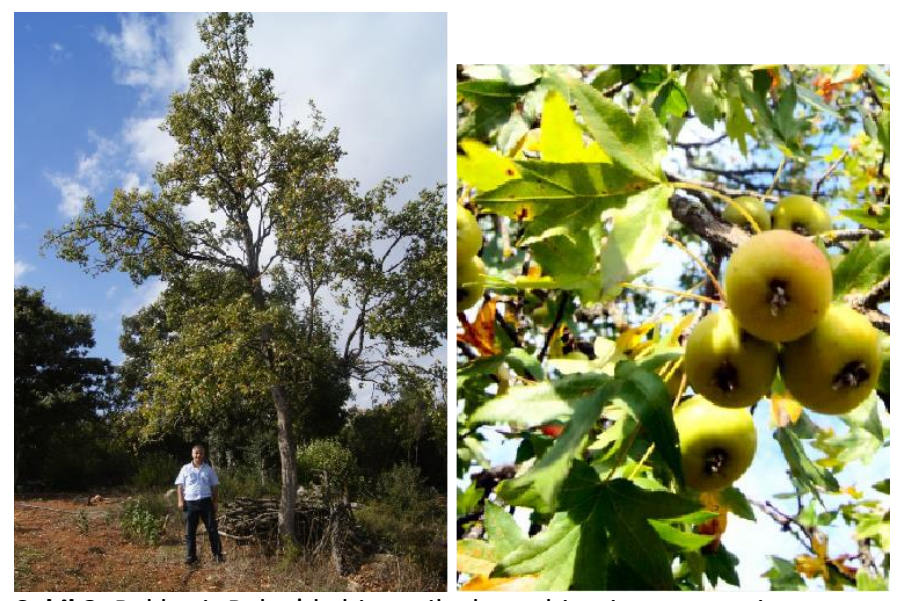

Şekil 3. Balıkesir Balya'da bir geyik elması bireyi ve meyvesi

Ege bölgesinde Denizli'nin Sarayköy ilçesi Yeşilyurt köyü Kulealtı, Kuyucak ve Ketenlik mevkilerinde tür tespit edilmiştir. Ayrıca Acıpayam ilçesinde de Ören ve Kelekçi köyleri başta olmak üzere yaygın olduğu bilinmektedir. Toplamda Denizli ili Sarayköy ilçesinde 26 adet geyik elması bireyi tespit edilmiştir. Tespit edilen bireyler üzerinde yapılan gövde çap ve ağaç boyu ölçümleri sonucu ortalama çap $10.7 \mathrm{~cm}$ ve ortalama boy $7.1 \mathrm{~m}$ olarak bulunmuştur. Denizli'de bireylerin tespit edildiği alanlarda kızılçam ormanları ve maki bitki örtüsü hakimdir ve mevcut bireyler genellikle kızılçam baskısı altındadır. Ortalama $833 \mathrm{~m}$. yükseltide ve çoğunlukla güney bakıdadır. Sarayköy-Hisar köyünde yakın zamana kadar 60-70 cm çapında bireylerin bulunduğu kaydedilmiştir. Ayrıca yakın çevreden toplanan tohumlardan Denizli Orman Fidanlığı'nda türün fidanları üretilmektedir.

Muğla'nın Kavaklıdere ve Menteşe ilçeleri Yeşilköy, Çayboyu köyü ve Cevizlik yaylası Sodra ve Sarısu mevkilerinde geyik elması bireyleri tespit edilmiştir. Toplamda Muğla ili Kavaklıdere ve Menteşe ilçelerinde 11 adet geyik elması bireyinde ölçüm yapılmıştır. Tespit edilen bireyler üzerinde yapılan çap ve boy ölçümleri sonucu ortalama çap $6.7 \mathrm{~cm}$ ve ortalama boy $4.2 \mathrm{~m}$ olarak bulunmuştur. Muğla'da bireylerin karaçam, kızılçam, ardıç türleriyle karışımda olduğu ve eşlik eden laden (Cistus) türleri olduğu gözlemlenmiştir. Ortalama 892 m yükseltide ve çoğunlukla kuzey bakıda olduğu belirlenmiştir.

İzmir'in Menemen ve Kemalpaşa ilçeleri Çukurköy, Turgutlar, Ovacık köyleri Değirmen boğazı, Şelale, Damlar Keyik Çeşmesi ve Bozalan yolu mevkilerinde geyik elmaları tespit edilmiştir. İzmir-Kemalpaşa ve Bornova'da başta Yenmiş, Çambel Yakaköy, Kuyucak, Damlacık, Çiçekli olmak üzere çok sayıda mevkide münferit olarak bulunmaktadır. Toplamda İzmir ili Menemen ve Kemalpaşa ilçelerinde 27 adet geyik elmasında ölçüm yapılmıştır. Bireyler üzerinde yapılan çap ve boy ölçümleri sonucu ortalama çap $16.4 \mathrm{~cm}$ ve ortalama boy $8.5 \mathrm{~m}$ olarak bulunmuştur (Şekil 4). İzmir'de bireylerin meşe kızılçam ve ahlat türleriyle karışımda olduğu gözlemlenmiştir. Ortalama 596 m. yükseltide ve çoğunlukla kuzey bakıda olduğu belirlenmiştir. 


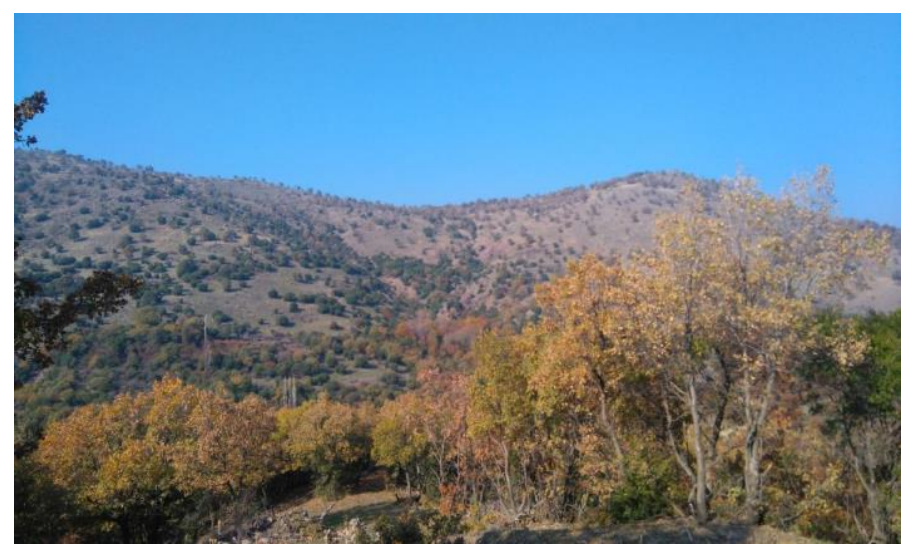

Şekil 4. Grup halde bulunan geyik elmaları, Çukurköy

Manisa-Salihli'de Gökköy, Çamurhamamı, Şirinyer ve Başlıoğlu köylerinde 200-600 m yükseltiler arasında serpili olarak bulunmaktadır. Manisa Sancaklı Bölgesindeki köylerde (Uzunçınar, Çeşmebaşı, Kayadibi, İ̆decik, Bozköy, Karaoğlanlı), Karakoca, Turgutalp ve Sultanyaylası köylerinde orman ve tarım arazisi kenarlarında rastlanmaktadır. Bu köylerde geyik elması, "kıy elması" ve "keycek" olarak da bilinmektedir. Meyveleri turşuların içine tat ve koku vermesi için az sayıda katılmaktadır. Ayrıca sirke de yapılmaktadır.

Çok sayıda arazi çalışması ve sorgulamaya rağmen, türün Bursa sınırlarında bireylerine rastlanmamıştır. Çanakkale'de serpili olarak ormanlarda bulunduğu nakledilmektedir. Bu ildeki dağılımını ve kümelendiği alanları tespit için geniş bir arazi çalışmasına intiyaç bulunmaktadır.

Güney Marmara ve Ege Bölgesi'nde sınırlı sayıda arazi çalışması ile toplamda 151 adet geyik elmasında ölçüm yapılmıştır. Özellikle Balıkesir ve Denizli'de türün daha fazla bireyinin bulunduğu gözlemlenmiştir. Mevcut ölçümlere göre, geyik elmasının il ve ilçelere göre yükselti dağılımı farklıık göstermiştir. Çalışılan alanlarda genel olarak geyik elmasının 225 m ile 1250 m'ler arasındaki dağılışı kaydedilmiştir (Şekil 5). Araştırma alanlarında belirlenen bütün geyik elması bireylerinin genel yükselti ortalaması ise yaklaşık $698 \mathrm{~m}$ olarak hesaplanmıştır.

Araştırma yapılan illerdeki doğal geyik elması bireylerinin bakıya göre sayılarının farklııık gösterdiği tespit edilmiştir. Ege ve Marmara bölgesindeki arazi taraması sonucu toplam 115 adet geyik elması için kayıt yapılmıştır. Bu bireylerin \%47.8'i güney, \%34.8'i kuzey, \%10.4'sı kuzeydoğu, \%2.6'sı güneydoğu, \%1.7'si kuzeybatı, \%0.9 güneybatı, \%0.9 doğu ve \%0.9 batı bakıda olduğu tespit edilmiştir (Şekil 6).

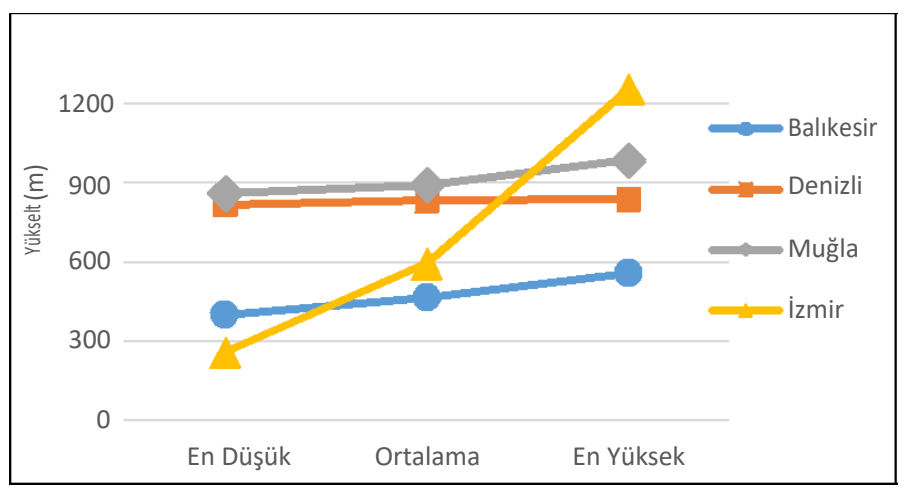

Şekil 5. Ölçümü yapılan geyik elması bireylerinin yükseltiye göre dağılımı.

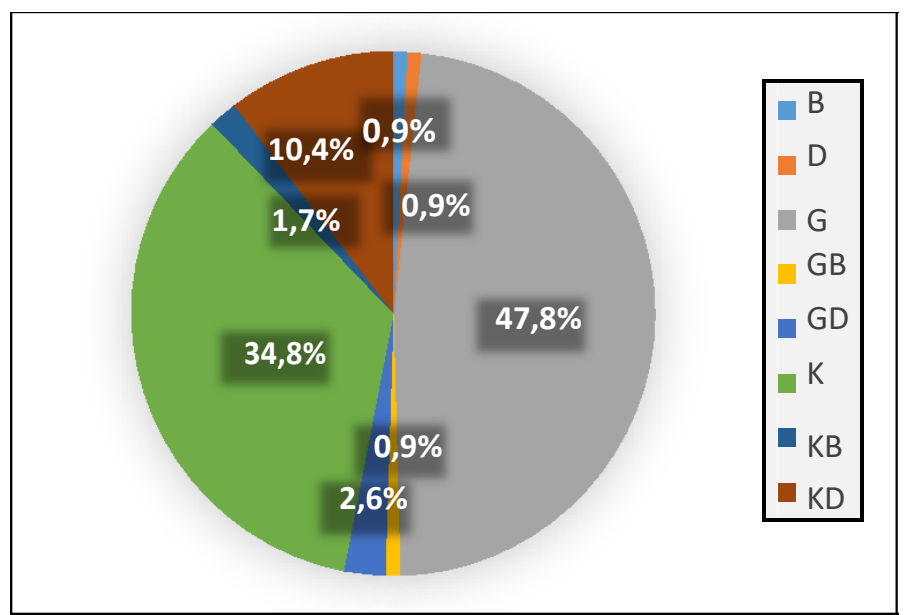

Şekil 6. Kaydedilen doğal geyik elması bireylerinin bakıya göre dağııımı.

\section{TARTIŞMA VE SONUÇ}

Geyik elması doğal yayılışının çok büyük kısmının ülkemizde olması, dekoratif görünümü, yaban hayatı işlevi, çok farklı arazilerde kullanım potansiyeli ve meyvesi bakımından ülkemizin önemli bir değeridir. Türün ülkemizdeki gen kaynaklarının mevcut olduğu yerler ile ilgili eksiklikler bulunmaktadır. Sınırlı sayıda arazi gezisi ile gerçekleştirilen mevcut çalışma ile Ege ve Güney Marmara bölgesindeki bazı gen kaynakları ortaya çıkarılmıştır.

Yapılan tespitler sonucu daha ayrıntılı arazi taramasıyla Güney Marmara ve Ege Bölgesi'nde çok daha fazla mevkide türün bulunabileceği öngörülmektedir. Ülkemizde daha fazla yetişme ortamını temsil eden türün gen kaynaklarının korunması önem arz etmektedir. Bu tür 
orman ağacı olmakla beraber, tarım arazilerinde de sıklıkla karşılaşılabilmektedir. Geyik elması bireylerinin özellikle tarım arazilerindeki tahribatını önlemek amacıyla yöre halkı bilinçlendirilmeli ve türün gen kaynağı korunmalıdır.

Geyik elması Ege, Marmara ve Batı Akdeniz bölgelerinde "Geyik Elması" "Kıy elması", "Gicik elma" gibi adlarla, Doğu Akdeniz Bölgelesinde ise "At Elması", "Geyicek" veya "Geyik Elması" adıyla bilinmektedir (Yılmaz ve Yüksel 2016). Geyik elmasının 2-3 cm çapa sahip olan taze meyveleri kekremsi bir tada sahiptir. Meyveleri önceleri elma yeşili, olgunlaşmaya başladığı sonbaharda ise sarımtırak esmer renk almaktadır (Baytop 1994). Yaban hayvanları ve kuşlar için meyveleri oldukça iyi bir besin kaynağıdır.

Yerel halk tarafından geyik elmasının meyve ve yaprakları sağlık ve genel kullanım amaçlı çeşitli işlemler yapılarak değerlendirilmektedir. Meyveleri normal sofralık meyve, sirke, turşu, pekmez, çay ve hoşaf (kak) olarak kullanılmaktadır. Halk arasında meyve ve yaprakları şeker hastalığı, nefes darlığı, kolesterol ve tansiyonu düşürme amaçlı olarak tüketilmektedir. Geyik elması fidanları üzerine elma çeşitleri aşılanabilmektedir. Ayrıca Yılmaz ve Ok (2012) ve Yılmaz ve Yüksel (2016) tarafından da benzer bilgiler kaydedilmiştir.

Güney Marmara'da Balıkesir ve Çanakkale'deki yayılışlar, Ege Bölgesi'nde Denizli, Muğla, İzmir ve Manisa'da tespit edilen bireyler türün Akdeniz, Ege ve Güney Marmara Bölgesinde kesintisiz olarak yayılış yaptığını göstermektedir. Ege ve Marmara Bölgesi'ndeki diğer illerdeki muhtemel yayılışı ayrıca incelenmelidir. Daha ayrıntılı arazi taraması ile türün Güney Marmara ve Ege Bölgesi'nde çok daha fazla mevkide bulunabileceği anlaşılmaktadır.

Tespit edilen geyik elması bireylerinin tamamına yakını araştırma yapılan sahada orman alanlarındadır. Türün genel olarak orman içinde serpili olarak bulunması, başta kuşlar olmak üzere yaban hayvanları tarafından taşındığını göstermektedir. Literatür bilgilerine göre (Yılmaz ve Yüksel, 2016), 200 m'lerden 1600 m'lere kadar yayılış gösteren türün Ege ve Güney Marmara'da orman ve özel arazilerde çok geniş pontansiyel değerlendirme alanı bulunmaktadır. Orman alanlarında özellikle ormanın dış sınırlarında, kapalıığın düşük olduğu taşlık alanlarda ve bilhassa yol kenarlarında mutlaka kullanılmalıdır. Yüksek rakımlara kadar çıkabilen bu tür bulunduğu yerlerde yaban hayvanları için de iyi bir besin kaynağı durumundadır.

Doğada serpili olarak bulunan bu tür, amenajman planlarında amaca ve kullanıma göre (tali tür, biyoçeşitlilik, bal ormanı, orköy, gelir getirici tür, vb.) fonksiyonlara dâhil edilmelidir.

Geyik elmasının doğal yayılış gösterdiği bölgelerde, bu türün önemi hakkında farkındalık oluşturmak ve bilgilendirmek kapsamında türü tanıtıcı proje ve programlar yürütülmelidir.

Orman içinde ve kenarlarında bulunan M.trilobata bireyleri çevresinde uygulanacak silvikültürel müdahalelerde, bu türü koruyucu işlemler yapılmalıdır. Hatta genetik çeşitliliğini arttırmak amacıyla uygun alanlarda tür doğal olarak gençleştirilmeli, tohum ekimi ya da fidan dikimi yapılarak çoğaltılmalıdır.

Geyik elması vejetasyon başlangıcıyla açan beyaz çiçekleri ve sonbahar aylarında yapraklarının görünümü ile son derece dekoratif bir türdür (Yaltırık 1966; Yılmaz 2008). Türkiye'den götürülerek yurtdışında yetiştirilmiş ve süs bitkisi olarak değerlendirilmektedir. Süs bitkisi özelliğinden dolayı doğal yayılış alanlarına yakın kent içi ağaçlandırma ve kırsal yerleşim yerlerinin park ve bahçe ağaçlandırmalarında kullanılabilecek türlerdendir (Ürgenç 1998; Yılmaz ve Ok 2012). Ayrıca mezarlıklarda da mutlaka değerlendirilmelidir.

Aşılı geyik elması meyve üretimi için doğadaki uygun genotipler belirlenmelidir. Tespit edilen genotiplerle meyve üretimi ve ex-situ korumaya dönük olarak uygun yerlerde aşıı ve aşısız bahçeler kurulmalıdır.

\section{TEŞEKKÜR}

Bu proje Bursa Teknik Üniversitesi BAP Koordinatörlüğü tarafından 2015-01-016 proje numarası altında desteklenmiştir. 


\section{KAYNAKLAR}

Baytop T (1994) Türkçe Bitki Adları Sözlügü. Atatürk Kültür, Dil Tarih Yüksek Kurumu. TDK Yayınları, Ankara.

Boratyński A, Browicz K and Zieliński J (1992) Chorology of trees and shrubs in Greece. Polish Acad. Sci., Inst. Dendrol., Poznań.

Browicz K and Karaca H (1993) Eriolobus triobatus (Pairet) Roemer in Turkey. The Karaca Arboretum Magazine, Vol.II, Part 2, Yalova

Browicz K (1982) Chorology of trees and shrubs in South-West Asia and adjacent regions, V:1, Poznan, p.48.

Gültekin HC, Yücedağ C, Çalışkan S (2007) Geyik Elması (Eriolobus triolobatus (Poir) Roeme.), Tohumu Üzerine Bazı Araştırmalar, i.Ü. Orman Fak. Derg., Seri A, 57(1): 31-47.

Gültekin HC (2011) Eriolobus triolobatus (Pair) Roeme. Orman ve Av Dergisi, Mart-Nisan (2): 36-39.

Işık S, Dönmez AA (2004) Pollen morphology of the three pomoid genera x Malosorbus Browicz, Mespilus L, and Eriolobus (Ser.) Roemer (Rosaceae). Hacettepe J. Biol. Chem. 33: 65-75.

Korakis G, Poirazidis K, Papamattheakis N and Papageorgiou A (2006) New localities of the vulnerable species Eriolobus trilobatus (Rosaceae) in northeastern Greece, In: Proceedings of IV BBC, Plant, fungal and habitat diversity investigation and conservation, Sofia, pp.422-426.
Küçük M, Ülgen H ve Finkral A (2008) Orman biyolojik çeșitliliğinin fazla bilinmeyen yönleri. Ülgen ve Zeydanlı ((Ed.) Orman ve Biyolojik Çeşitlilik, s.53-96, Doğa Koruma Merkezi (DKM), Ankara.

Qian G, Liu L and Tang G (2006) A New Section in Malus (Rosaceae) from China. Ann. Bot. Fennici, 43: 68-73.

Türkmen N, Kırıcı S, Özgüven M, İnan M, Kaya DA (2004) An investiagation of dye plants and their colourant substances in the eastern Mediterranean region of Turkey. Botanical Journal of the Linnean Society, 146:71-77.

Ürgenç S (1998) Ağaçlandırma Tekniği, i.ü. Orman Fak. Yayın No: 3994/441, Emek Matb., ìstanbul.

Yaltırık F (1966) Türkiye florası için yeni bir tespit Sorbus trilobata Labll. i.Ü. Orman Fak. 16(1):156-159.

Yılmaz M ve Ok T (2012) Geyik Elması (Malus trilobata C.K. Schneid.)'nın bazı biyolojik, ekolojik ve etnobotanik özellikleri, KSÜ Doğa Bil. Der., Özel Sayı, 156-160.

Yılmaz M (2008) Optimum germination temperature, dormancy, and viability of stored non-dormant seeds of Malus trilobata (Poir). C.K. Schneid., Seed Science and Technology, 36:747-756.

Yılmaz M, Yüksel MC (2016) Geyik Elması (Malus trilobata CK Schneid.)'nın Etnobotanik Özellikleri ve Fidan Üretimi. El-Cezeri Journal of Science and Engineering, 3(1). 